\title{
The Relationship between Emotional Intelligence and Speaking Skills of Iranian Advanced EFL Learners
}

Zohre Esmaeeli, Masoud Khalili Sabet and Yadollah Shahabi

Department of English language and literature, Guilan University, Rasht, Iran

Corresponding Author: Masoud Khalili Sabet E-mail: sabetma2002@yahoo.com

\begin{tabular}{l} 
ARTICLE INFO \\
\hline Article history \\
Received: February 14, 2018 \\
Accepted: April 20, 2018 \\
Published: September 01, 2018 \\
Volume: 7 Issue: 5 \\
Advance access: July 2018 \\
\hline
\end{tabular}

Conflicts of interest: None Funding: None

\begin{abstract}
The role of emotional intelligence as a significant factor contributing to academic achievement was central in the area of research for several years. In second language learning research, personal and social skills seems to be critical as individual differences in language production. In this regard, this study has attempted to investigate the relationship between emotional intelligence and speaking skills of Iranian advanced EFL learners. In order to achieve this goal, 96 advanced EFL learners including 48 males and 48 females were randomly selected from eight institutes in Tehran. The design of the study is a quantitative, non- experimental research utilizing a correlational approach. The data were gathered through an EQ questionnaire (namely EQ- i: S, designed by Bar- On), and speaking test (from ILETS samples of speaking tests in the form of individual interview). The value of Pearson correlation coefficient indicated that there was a significant relationship between emotional intelligence and speaking score of advanced EFL learners. The findings of the present study which denoted the role of EQ in speaking ability can be efficiently implemented in educational system through social- and- emotional- learning programs to improve students' oral proficiency in language classroom. And it is the job of English teachers to exploit students' full potential in order to facilitate language learning.
\end{abstract}

Key words: Emotional Intelligence, Advanced EFL Learners, Academic Achievements, Speaking Skills

\section{INTRODUCTION}

For years, intelligent quotient or IQ was the center of psychologists' attention in order to appraise people for work and education. Howard Gardner proposed the theory of multiple intelligences, and developed his model in 1983. He introduced eight types of intelligences (including mathematical, musical, linguistic, visual-spatial, physical, intuitive, intrapersonal and interpersonal intelligence) rather than a single intelligence. According to Gardner (1999), all human beings know the world through these eight types of intelligences. But it seemed that having a high level of IQ was not enough to have success in work and education. There were brilliant people unmotivated and out of control by negative emotions who were never expected to obtain considerable academic achievements; on the other side, there were people really good at work and education who knew how to solve real- life problems, to stay motivated, self-controlled, optimistic and calm in tough situations.

High level of IQ can be very beneficial to succeed, but it is not the only factor a person needs to possess in order to achieve his goals. Another important factor which leads people to be successful in school, job and life is related to a non- cognitive intelligence called "Emotional Intelligence" or EI. According to Goleman (1995), emotional intelligence is a different way of being smart and bright with feelings and emotions.

People with highly developed emotional intelligence are less defensive and more open to criticize. They are able to solve efficiently a wide variety of emotional problems. Physical health, stress-management, goal setting, optimism, good relationships, and good decision making are some outcomes of emotional intelligence. In fact, circle of EI is surprisingly much broader.

The role of emotional intelligence as a factor associated to individual differences in language learning has been center of the research for several years. It has been considered alongside other factors such as IQ, language aptitude, learning style and strategies, motivation, attitude, and personality trait that depicts individuals' unique abilities in language acquisition. Consequently, emotional intelligence seems to be indispensable in the process of language learning.

Oral language skills are an essential part of learning a foreign language, and the most considerable problem for the learners in countries where English is considered as a foreign language, is that they are weak in oral communication. As a result, speaking has been always a challenge for the learners. The present study seeks to investigate the relation- 
ship between emotional intelligence and speaking skills of EFL learners in line with proving the claim that emotional intelligence contributes to speaking skills at advanced level.

\section{LITERATURE REVIEW}

A review of literature in the area of education shows an increasing interest in research associated to emotional intelligence and academic achievements. Second language learning as an educational field of study is an area of inquiry in such investigations.

\section{Emotional Intelligence}

In 1920 Edward Thorndike proposed the notion of "social intelligence" as the first concept related to emotional intelligence. Later, in 1939 Wechsler explained the influence of non- intellective factors on "intelligent behavior" in the field of psychology. He argued our traditional models of general intelligence would not be complete without describing emotional factors (Wechsler, 1943). In 1983 Howard Gardner introduced his known model of "multiple intelligences". $\mathrm{He}$ proposed intrapersonal and interpersonal intelligence embedded in cognitive intelligence as the two complimentary components. Few later, Reuven Bar- On in 1985 introduced the term "Emotional Quotient" (EQ), for the first time, in his doctoral dissertation proposing a conceptual and psychometric model of emotional intelligence separated from cognitive intelligence. Today, Bar- On's model is one of the three influential models of EI in psychology.

At the beginning of the 1990s, Mayer and Salovey published articles on emotional intelligence providing first review of areas of emotional intelligence more precisely. Their model of EI was based on individual's performance on solving emotional problems known as the "ability model".

During this time, further investigations of EI were developed, especially in the brain sciences. 1994-1997, Daniel
Goleman, a science journalist, published his popular book named "Emotional Intelligence". He borrowed the term from Bar-On, and developed it through several papers (Ciarrochi, at all. 2001).

\section{Bar- On's model of EI}

According to literature related to emotional intelligence, the initial definitions of EI arose in the work of Renuven BarOn. He defines EI or EQ as "a cross section of interrelated emotional and social competencies, skills and facilitators that determine how effectively we understand and express ourselves, understand others and relate with them, and cope with daily demands." (Bar-On, 2006, p.3). The present study has been conducted based on Bar- On's model of EI.

He considered EQ as a counterpart to IQ, and as a set of emotional and social abilities which help individuals cope with social life needs. Bar-On's idea of EQ is related to the ability of understanding and managing emotions, and the degree to which a person possesses efficient social skills (BarOn, 2000). Bar- On's EQ- inventory scale including five elements (Bar- On, Maree, \& Elias, 2007, p.4) has briefly shown in table 2.1 .

\section{Speaking Skills}

Learning a language is a difficult, exhausting and stressful work in which learners mostly use the language with lots of mistakes. Oral language performance has always been a challenge for language learners, in countries in which English is considered as a foreign language; therefore, there has been a weak performance among English students in speaking skill. In this case, as noted by Guo and Wang (2013), students' ability in spoken language is always much lower than their written skills, and although they have a good grasp of vocabulary and grammar, most of which cannot communicate confidently in English.

Table 2.1. The bar- On EQ-i scales

\begin{tabular}{lll}
\hline EQ-i scales & & The EI competency assessed by each scale \\
\hline \multirow{3}{*}{ Intrapersonal } & Self-regard & To accurately perceive, understand and accept oneself \\
& Emotional Self-awareness & To be aware of and understand one's emotions and feelings \\
& Assertiveness & To effectively and constructively express one's feelings \\
& Independence & To be self-reliant and free of emotional dependency on others \\
& Self-actualization & To strive to achieve personal goals and actualize one's potential \\
Empathy & To be aware of and understand how others feel \\
Interpersonal & Social responsibility & To identify with one's social group and cooperate with others \\
& Interpersonal relationship & To establish mutually satisfying relationships and relate well with others \\
Stress management & Stress tolerance & To effectively and constructively manage emotions \\
& Impulse control & To effectively and constructively control emotions \\
Adaptability & Reality testing & To objectively validate one's feelings and thinking with external reality \\
& Flexibility & To adapt and adjust one's feelings and thinking to new situations \\
Problem-solving & To effectively solve problems of a personal and interpersonal nature \\
& Optimism & To be positive and look at the brighter side of life \\
& Happiness & To feel content with oneself, others and life in general
\end{tabular}


According to Krashen's hypothesis of affective filter (1982), motivation, anxiety, and self- confidence are emotional factors contributed to language learning. Through a glance over these factors, it seems that they are indirectly related to emotional intelligence.

\section{Motivation}

Of all affective factors intervening in language learning, motivation has probably a crucial role in successful language learning (Guo and Wang, 2013). And teachers know that learners' interest in learning can eliminate most of affective and cognitive barriers in the way of learning. High motivation and positive attitudes toward a foreign language may encourage learners to take part prominently in class activities which result to greater performance in oral communication.

Regarding to Bar- On's model, motivation can be related to self- actualization and optimism. Marzban and Sadeghi (2013) investigated the role of motivation in English speaking ability in Iranian EFL university students, and found a positive relationship between these two factors. Based on their research study, motivated students scored higher than the others in speaking tests.

\section{Anxiety}

Negative emotions such as anxiety, stress, depression, frustration and anger imped language learning. Anxiety is probably regarded as the prominent factor which makes language learning difficult especially in the area of speaking. Shakara$\mathrm{mi}$ (2015) in his study indicated that students experience more anxiety in their language classes than in other classes. It is acknowledged that anxiety is associated with feelings of uneasiness, frustration, self- doubt, and apprehension which results poor performance on both oral and written proficiency (Guo and Wang, 2013). It also directly reduces students' willingness to communicate (Alavinia and Agha Alikhani, 2014).

In a study of native Spanish speakers learning English, Gregersen found that anxious learners made more errors and corrected themselves more than less anxious learners (cited in Brown, 2007) which may indicate a low level of self- confidence in such students.

Philips (1992) showed that there is a negative relation between language anxiety and oral performance. The sample for his study was students enrolled in French classes at Southwestern, a private liberal arts university from seventeen to twenty-one; including thirty-five females and nine males. He concluded that students who experience negative feelings of anxiety frightened by oral evaluation are not likely to show positive attitudes toward language classes, and they are not willing to take more classes than required.

\section{Self-confidence}

Learners with high self- confidence are more motivated, cooperative, and responsive in communication. They are willing to take part in conversations, share ideas, and freely express themselves in front of others. As MacIntyre, Dornyei,
Clement, and Noels (1998) suggested, self- confidence positively contributes to willingness to communicate in a second language. Therefore, it can be noticed that self- confidence may correlate directly to oral performance. Self- confidence can be related to self- regard, self- awareness, assertiveness and independence in Bar- On's model of EI.

In a study (Hamouda, 2013) carried out on 159 Saudi Arabia EFL students in Qassim University, Hamouda found considerable number of silent students unwilling to respond to the teacher in English classes due to their low English proficiency, shyness, lack of confidence, and fear of making mistakes, as well as negative evaluation by peers.

\section{METHODOLOGY}

\section{Participants}

Participants of the present study were 96 (48 males and 48 females) Persian speakers studying English as a foreign language at advanced level which were randomly selected from eight institutes in Tehran, Iran. It is worth to note that they have never been in an English speaking country yet. And in order to control the effect of age in EQ level, they were selected around 15 years of age.

\section{Instruments}

\section{General language proficiency test}

The first instrument was general language proficiency test which was used to have a homogeneous group of candidates at advanced level. For this purpose, a 40-item test of ILETS proficiency test including three parts (vocabulary, grammar, and cloze test) were utilized. The participants responded to the test in 30 minutes.

\section{EQ test}

Instrument to measure participants' $E Q$ was a translated version of EQ-I 2.0 developed by Bar- On in a form of a self- report assessment including 90 items in 15 subscales consists of problem solving, happiness, stress tolerance, independence, emotional self- awareness, reality testing, interpersonal relationship, self- actualization, optimism, self- reliance, impulse control, empathy, assertiveness, social responsibility, and flexibility. It should be noted that the original version of the test was included 133 items, but in order to eliminate participants' tiredness effect on the test, the researcher preferred to use a reduced version named EQi: S (short version) to assess candidates' EQ.

\section{Speaking test}

In order to measure candidates' speaking ability, a speaking sample task selected from ILETS samples of speaking tests in a form of individual interview was conducted. According to the part one of ILETS speaking test, the examiner asked examinee to talk about his/her home town and accommodation. Part two was related to individual long turn for which examinee was asked to talk about something which was im- 
portant to him/her. And in the last part, there was a two- way discussion between examiner and examinee about advertisement and changing people's value.

\section{Procedure}

Through a test of general language proficiency, 96 participants were selected in advanced level. At the next step, in order to measure participants' EQ level the EQ questionnaire were given to the participants. To avoid deviating from the original test, a reverse translation has also done to match items with the original questionnaire. The participants answered 90 items on the test in 40 minutes.

In final step, individual interview was conducted in recorded voice. Scoring the oral data was done according to rating scale prepared by Farhady, Birjandi and Djafarpour (1994) for speaking tests. A second rater who was a native-like teacher with the experience of ten years of teaching English assigned separate scores to participants' speaking skill. In order to reach an acceptable agreement, a test of inter- rater reliability was done, and the result presented in the following sections.

\section{Data analysis}

The data related to EQ were gathered from EQ test based on answers in a Likert Scale including: strongly disagree, disagree, slightly agree, and strongly agree. Most of the questions in the test were parallel which tended to extract reliable answers from the candidates. This way if a learner responded carelessly to a question, the parallel question assessed him again. Also, questions were not evidence pertaining to morality or spirituality which everyone desires to possess; they examined indirectly learners' emotional skills in different situations.

Scoring candidates' speaking test was done with the help of a native- like teacher based on typical guidelines from Farhady, Birjandi and Djafarpour (see appendix), in a rating scales from 1 to 6 considering candidates' pronunciation, sentence structure, vocabulary, fluency and comprehension. The scoring process was done by two raters with an acceptable reliability level indicating appropriate agreement between the two.

\section{RESULTS AND DISCUSSION}

In order to investigate the research question as "Is there a significant relationship between emotional intelligence and speaking skills of advanced EFL learners?", it was formulated in the following null hypothesis:

There is not any significant relationship between emotional intelligence and speaking skills of advanced EFL learners.

The analysis provided a descriptive statistics for all students in terms of their speaking abilities, and the result was showed in table 4.1 .

In order to meet assumptions for utilizing correlational statistics it was needed to examine normality of distribution of the data; therefore, a test of normality was done. The level of significance for Shapiro-Wilk, which can be seen in table 4.2, was higher than.05; accordingly, the researcher could make a sure that learners' speaking scores had been laid in a normal distribution.

Because participants' speaking scores were subjective, there was a need for a second rater to obtain another set of oral data based on the same rating scales (Farhady, Birjandi and Djafarpour guidelines).

The value of Kappa indicating the degree of agreement between two raters was gained.702 (see table 4.3).

The data related to students' EQ score in terms of minimum and maximum score, mean, standard deviation, and variance were presented in table 4.4.

For participants' EQ scores, again, normality of distribution was examined (Table 4.5) and the result indicated that their EQ scores were also normal in distribution (Level of significance for Shapiro-Wilk in this case was equal to.075 which was higher than.05).

In order for investigating research question, or indicating correlation between participants' speaking score and their EQ score a test of correlation was done, and the result was showed in the following scatter diagram (Figure 4.1).

According to the scatterplot for candidates' speaking score and EQ score, we see the dotes move in a direction from lower left to upper right. When this happens, we say that there is a positive correlation between two variables (EQ score as an independent variable and speaking score as a dependent

Table 4.1. Descriptive statistics for speaking scores

\begin{tabular}{lcccccc}
\hline Descriptive statistics & \multicolumn{1}{c}{} & & & & \\
\hline & N & Minimum & Maximum & Mean & Standard deviation & Variance \\
\hline Speaking Score & 96 & 9.00 & 23.00 & 15.958 & 2.868 & 8.230 \\
Valid N (list wise) & 96 & & & & & \\
\hline
\end{tabular}

Table 4.2. Test of normality for speaking scores

\begin{tabular}{|c|c|c|c|c|c|c|}
\hline \multicolumn{7}{|c|}{ Tests of Normality } \\
\hline & \multicolumn{3}{|c|}{ Kolmogorov-smirnov ${ }^{a}$} & \multicolumn{3}{|c|}{ Shapiro-wilk } \\
\hline & Statistic & df & Sig. & Statistic & df & Sig. \\
\hline Speaking score & 0.100 & 96 & 0.020 & 0.978 & 96 & 0.116 \\
\hline
\end{tabular}

a. Lilliefors Significance Correction 
Table 4.3: Inter- rater reliability related to speaking scores

\begin{tabular}{|c|c|c|c|c|}
\hline \multicolumn{5}{|c|}{ Symmetric measures } \\
\hline & Value & Asymptotic standardized error ${ }^{a}$ & Approximate $T^{b}$ & Approximate significance \\
\hline \multicolumn{5}{|c|}{ Measure of agreement } \\
\hline Kappa & 0.702 & 0.069 & 15.843 & 0.000 \\
\hline $\mathrm{N}$ of valid cases & 96 & & & \\
\hline
\end{tabular}

a. Not assuming the null hypothesis.

b. Using the asymptotic standard error assuming the null hypothesis.

Table 4.4. Descriptive statistics for EQ scores

\begin{tabular}{lcccccc}
\hline Descriptive Statistics & \multicolumn{1}{c}{} & & & \\
\hline & N & Minimum & Maximum & Mean & Standard deviation & Variance \\
\hline EQ score & 96 & 253.00 & 384.00 & 327.479 & 31.196 & 973.321 \\
Valid N (list wise) & 96 & & & & & \\
\hline
\end{tabular}

Table 4.5: Test of normality for EQ score

\begin{tabular}{lccccccc}
\hline Tests of normality & & & & & \\
\hline & \multicolumn{3}{c}{ Kolmogorov-Smirnov } & & \multicolumn{3}{c}{ Shapiro-Wilk } \\
\cline { 2 - 3 } & Statistic & df & Sig. & & Statistic & Df & Sig. \\
\hline EQ score & 0.074 & 96 & $0.200^{*}$ & & 0.976 & 96 & 0.075 \\
\hline
\end{tabular}

a. Lilliefors significance correction

Table 4.6: Pearson product- moment correlation

\begin{tabular}{lcc}
\hline Correlations & Speaking score & EQ score \\
\hline $\begin{array}{l}\text { Speaking score } \\
\text { Pearson }\end{array}$ & 1 & $0.588^{* *}$ \\
Correlation & & \\
Sig. (2-tailed) & & 0.000 \\
$\mathrm{~N}$ & 96 & 96 \\
EQ score & & 1 \\
Pearson & $0.588^{* *}$ & \\
Correlation & & \\
Sig. (2-tailed) & 0.000 & 96 \\
N & 96 & \\
\hline
\end{tabular}

**. Correlation is significant at the 0.01 level (2-tailed).

variable). This means that the more emotionally intelligent the learner, the more proficient $\mathrm{s} / \mathrm{he}$ is in speaking ability.

In order to have precise values a test of Pearson's product- moment correlation was done, and the result was showed in table 4.6 .

As Pearson correlation analysis indicated $(n=96, r=.588$, $\alpha<.01$ ), a significant relationship appeared between participants'speaking scores and their EQ level. Therefore, the null hypothesis was rejected.

\section{DISCUSSION}

The present study through conducting a correlational statistics demonstrated significance relationship between emotional intelligence and speaking abilities of advanced EFL learners. Positive value of correlation coefficient showed

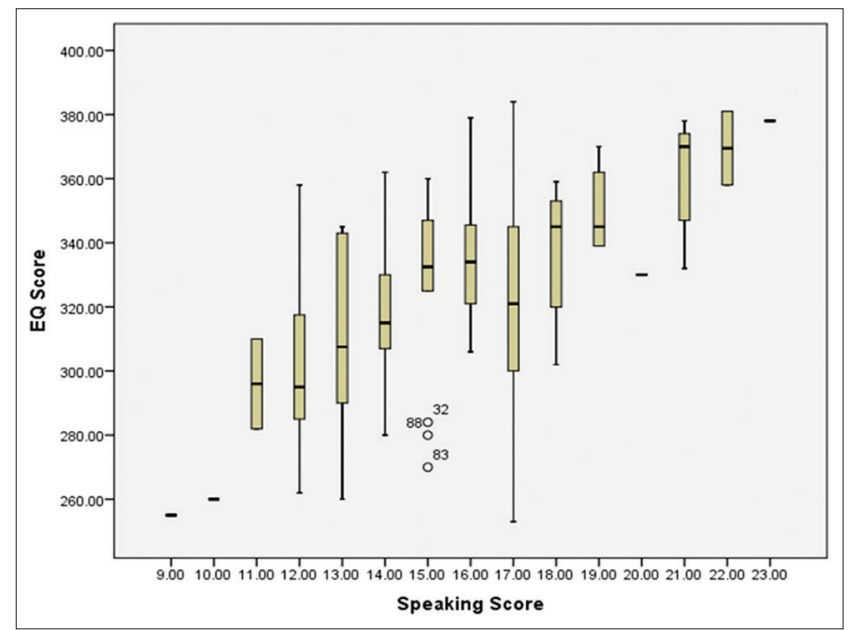

Figure 4.1. Scatter diagram for EQ Scores

that the more emotionally intelligent the learner, the more proficient $\mathrm{s} / \mathrm{he}$ is in speaking skills. This is supported by several studies in related areas of language proficiency. Ketabdar, Yazdani, and Yarmohammadi (2014) concluded that there was a positive relationship between EI and willingness to communicate among Iranian EFL learners through examining four factors of EI including interpersonal relationship, empathy, assertiveness, and emotional self- awareness. Barani and Shakib (2011) investigated the relationship between EI and language proficiency and found positive relationship between these two variables. Guo and Wang (2013) examined the role of affective factors in oral English and found a positive impact. And Genc, Kulusakli and Aydin (2016) concluded that there was a positive relationship between EI and productive language skills. Regarding to components of EI based on Bar- On's model, interpersonal skills lead students to have good relationships and effective communications, and try to develop empathy with peers. Intrapersonal skills help them be aware of their emotions, be self- regulated and self- actualized striving to achieve personal goals. Stress- management help them to eliminate language anxiety, and assist them to be more confident in oral skills. Adaptability leads them effectively solve problems while encountered 
to challenges of language learning. And general mood propels them to be positive and look on the bright side of life.

\section{CONCLUSION}

The focus of the present study was to investigate the relationship between emotional intelligence and speaking skills of advanced learners which resulted to find a positive value for correlation indicating the fact that emotionally intelligent learners are equipped to personal and social skills related to their EQ which help them develop successfully their oral proficiency.

It seems that there are possibilities for the study in other areas of language skills including listening, reading and writing, or even in the field of language assessment. And it would be possible to generalize the findings of this study through further investigations to other areas of language learning.

\section{Pedagogical Implications}

Second language learning is an intricate, tedious process which needs to apply all potential resources in order to reach optimal attainment. To fully understand the complexity of language-learning process, English teachers should take into account both internal and external mechanisms in this process (Alvandnia \& Agha Alikhani, 2014). In this regard, emotional intelligence has been distinguished as an important, internal factors associated to individual differences in academic environment. For this reason, English teachers should be aware of the concept of EI and make the effort as much as possible to develop students' abilities in this field (Barani \& Shakib, 2011). They should embed EI- related strategies in language teaching, and facilitate cooperative learning in the form of discussion groups in which learners are asked to express their feelings openly and share those feelings with others, and help them foster their self- confidence, having good relationships with the classmates, and reduce language anxiety this way.

In fact, through emotional- intelligence enhancement, students will be more active in oral communications and tend to achieve high level of proficiency in language classes.

In addition, educational system should also take into account prominent findings in the area of research related to EI and language proficiency. And curriculum designers take into consideration the value of EI- training programs in academic settings. If we believe that EI is an important factor in language learning, and if we believe that it can be enhanced, language policy makers are expected to include EI- related programs to raise emotional literacy of language learners (Pishgadam, 2009).

Social and emotional learning can be a collaborative program with the help of teachers, curriculum designers and parents in order to enhance students' personal and social skills. The most effective program, according to Elias (cited in Edutopia, 2001), takes no less than three years of training to show the beneficial results. Accordingly, it needs to fulfill a comprehensive set of instructions concerned with EI regarding to students' emotional needs in academic environment. EI- enhancing programs make actually a new vision of education that pays a special attention to emotional issues (Edutopia, 2001) and developing such programs make noticeable improvement in learning outcomes.

\section{REFERENCES}

Alivinia, P. Agha Alikhani, M. (2014). Willingness to communicate reappraised in the light of Emotional intelligence and gender differences. Science Direct, 98, 143-152.

Barani, GH. \& Shakib, S. (2011). The relationship between emotional intelligence and language proficiency of Iranian high school students. Science Direct, 30, 1603-1607.

Bar-On, R. (2000). Emotional and social intelligence: Insights from the emotional quotient inventory (EQ-I). In R. BarOn, \& J. D., Parker (Eds.), The handbook of emotional intelligence, (pp. 363-388). Jossey- Bass, San Francisco.

Bar-On, R. (2006). The Bar-On model of emotional-social intelligence (ESI). Psicothema, 18, 13-25.

Bar- On, R., Maree, J. G., \& Elias, M. J. (2007). Educating people to be emotional intelligent. Johannesburg: Heinemann.

Brown, H. D. (2007). Principle of language learning and teaching. ( $5^{\text {th }}$ ed.). New York: Longman.

Ciarrochi, J. Chan, A. Caputi, P. Roberts, R. (2001). Measuring emotional intelligence. In Ciarrochi, J. Forgas, J. P. Mayer, J. D. (2001). Emotional intelligence in everyday life. (pp. 25-46). New York: Psychology Press.

Edotopia team. (2001, February 22). Emotional intelligence is the missing piece. Retrieved from: https://edutopia. org/social-emotional-intelligence-learning-education.

Farhady, H \& Djafarpour, A., (1994), Testing language skills from theory to practice. (19 ${ }^{\text {th }}$ ed.). Tehran: SAMT

Gardner, H. (1999, February). Who owns intelligence? The Atlantic Monthly.

Genc, G., Kulusakli, E., \& Aydin, S. (2016). The relationship between emotional intelligence and productive language. An International Online Journal. 16(1), 91-105Goleman, D. (1995). Emotional intelligence: Why it can matters more than IQ. New York: Bantam Books.

Goleman, D. (1995). Emotional intelligence: Why it can matters more than IQ. New York: Bantam Books.

Guo, M. \& Wang, Y. (2013). Affective factors in oral language teaching and learning. Higher Education of Social Science. 5, (3), 57-61.

Hamouda, A. (2013). An exploration of cases of Saudi students' reluctance to participate in the English language classroom. International Journal of English Language Education, 1(1), 17-34.

Ketabdar, Z., Yazdani, S., \& Yarahmadi, M. (2014). The relationship between emotional intelligence and willingness to communicate among Iranian EFL learners. European Online Journal of Natural Social Sciences. 3(3), 637-650.

Krashen, S. (1982). Principal and practice in second language acquisition. Oxford: Pergamon.

MacIntyre, P. D. Dornyei, Z., Clement, R. \& Noelz, K. (1998). Conceptualizing willingness to communicate in a L2: A situational model of L2 confidence and affiliation. Modern Language Journal. 82, 545-562.

Marzban, H., \& Sadeghi, F. (2013). A study of the impact of motivation and attitude on speaking in academic context: A case of Iranian EFL university students. International Journal of Language and Applied Linguistics world, 3(4), 154-177. 
Philips, E. (1992). The effects of language anxiety on students' oral test performance and attitudes. Modern Language Journal, 76, 12-26.

Shakarami, A. (2015). How emotional intelligence and language learning strategies interact in an EFL setting. In- ternational Journal of Applied Linguistics and English Literature. 4(2), 229-237.

Wechsler, D. (1943). Nonintellective factors in general intelligence. Journal of Abnormal Social Psychology, 38, 100-104.

\section{APPENDIX}

\begin{tabular}{|c|c|}
\hline \multicolumn{2}{|c|}{ Pronunciation } \\
\hline 6 & Phonetically acceptable pronunciation throughout \\
\hline 5 & Few phonemic errors but never hindering comprehension \\
\hline 4 & Occasional phonetic errors necessitate attentive listening \\
\hline 3 & Frequent phonemic errors require frequent demands \\
\hline 2 & Constant phonemic errors make comprehension very hard \\
\hline 1 & Sever errors make understanding virtually impossible \\
\hline \multicolumn{2}{|c|}{ Sentence structure } \\
\hline 6 & Almost no error \\
\hline 5 & Few insignificant errors only \\
\hline 4 & Occasional petty errors but no problem with understanding \\
\hline 3 & Frequent errors occasionally interfere with meaning \\
\hline 2 & Constant errors interfere with understanding \\
\hline 1 & Sever errors make understanding virtually impossible \\
\hline \multicolumn{2}{|c|}{ Vocabulary } \\
\hline 6 & Appropriate and extensive use of words in any domain \\
\hline 5 & Appropriate use of vocabulary to discuss general topics \\
\hline 4 & Occasional use of appropriate words which do not affect the massage \\
\hline 3 & Frequent use of appropriate words distort the massage \\
\hline 2 & Constant use of wrong words, limited vocabulary \\
\hline 1 & Inadequate basic vocabulary \\
\hline \multicolumn{2}{|c|}{ Fluency } \\
\hline 6 & Fluent and effortless speech like a native speaker \\
\hline 5 & Natural and continuous speech \\
\hline 4 & Fluent speech with occasional problems \\
\hline 3 & Frequent problems hinder fluency and demand greater effort \\
\hline 2 & Slow speech hesitant and sometimes silent \\
\hline 1 & Virtually unable to make connected sentences \\
\hline \multicolumn{2}{|c|}{ Comprehension } \\
\hline 6 & Comprehends everything \\
\hline 5 & Comprehends everything except for low-frequency items \\
\hline 4 & Comprehends nearly everything but needs occasional rephrasing \\
\hline 3 & Comprehends slower than normal \\
\hline 2 & Comprehends only slow and simple speech \\
\hline 1 & Comprehends very little of even simple and slow speech \\
\hline
\end{tabular}

